\title{
Identifying knowledge management processes and practices used for decision-making and knowledge sharing in the modern San community
}

\author{
$N$ SEWDASS ${ }^{l}$
}

\begin{abstract}
First People, such as the San community of Platfontein, are the holders of rich and complex knowledge systems that are very important for dispute resolution and decisionmaking. In order to ensure that these knowledge systems are maintained and sustained for future generations to benefit from, it is important to introduce and implement new approaches that can help to make intergenerational transmission of this valuable knowledge possible for the younger generation of San. While this community possesses a vast amount of unique knowledge, skills and competencies, these are at risk as the older generation of the San is ageing and passing on with very little of their knowledge and skills ever being transmitted to younger generations or documented and preserved for future generations to consult. Furthermore, the new generation of the San, which is referred to the modern San, are becoming more Westernised and are slowly losing their traditional culture and values. Hence, this study focuses on Knowledge Management processes and practices that are used in the modern San community for decision-making and knowledge sharing.
\end{abstract}

Keywords: knowledge management, knowledge sharing, indigenous knowledge, decision-making, knowledge, San community, Platfontein

\section{Background}

Knowledge Management (KM) is a growing global concern and helps overturn other prejudices such as marginalisation and discrimination. Indigenous knowledge systems are threatened by changes in the environment that hosts indigenous peoples' livelihoods. It is through better ecological management, recognising and affirming indigenous peoples' cultures, and active management of knowledge that these fragile and valuable systems of knowledge can continue to be transmitted (Crawhall, 2007:25).

Any society or community has its own peculiar way of evolving and in these communities, traditional beliefs and practices are important not only to the people who own and understand them but also to those who subscribe to a common societal value system (Kaniki \& Mphahlele, 2002:15). What is even more important is that these communities are presently facing rather complex human problems that were never experienced in the past, and

Nisha Sewdass is a Professor in the Department of Management Science: Strategy and International Management at the University of South Africa (UNISA). She is one of the academic researchers involved in the community-based participatory research project with the San community of PlatfonteinEmail: Sewdan@unisa.ac.za. 
in order to solve these problems, more complex solutions are required. Kaniki \& Mphahlele (2002:15) further state that "in order to deal with complex problems and facilitate development and manage change, the modern communities must borrow and adapt ideas and practices from other sources, including traditional (indigenous) and scientific communities".

Indigenous knowledge (IK) is usually known by various names such as traditional ecological knowledge, folk knowledge, or traditional knowledge. It is tacit in nature and practical in its value; it is kept in the form of wisdom in the memory of individuals and is unique to the holder of this knowledge (Ikoja-Odongo, 2004:174). This author states that IK occupies a central space in the lives of rural communities of developing countries because of their reliance on natural resources; influence of the environment; existence of a diverse knowledge of plants used in herbal medicines; poor health care systems in these societies; challenges presented by diseases, such as, HIV/AIDS, malaria and tuberculosis; conservation of traditions; and the availability of life skills in the form of experience and wisdom.

Kaniki \& Mphahlele (2002:15) also note that that there is a growing recognition of IK in making decisions, solving problems and dealing with societal development issues. This notion is also supported by the statement in the Editorial of the Indigenous Knowledge and Development Monitor (1993:1), which indicates that:

\section{knowledge produced by universities and research institutes around the world is gathered, documented and disseminated in a coherent manner. The same should be done with community-based, local or indigenous knowledge, most of which reinforces sustainable relationships between humans and their natural and social environments. This knowledge is passed down from generation to generation within communities. It should be included, alongside the more usual scientific knowledge, as part of national and international discussions on development and the strengthening of intellectual capacity.}

Although knowledge is essential for decision-making, what is more important is that the specific knowledge of local or indigenous communities is also taken into consideration when decisions are made about issues that involve these communities. Hence IK is vital and can be used for dispute resolution and decision-making. However, before this can happen, this knowledge must first be identified in these communities and it must be understood how it is applied and what challenges it poses for the community. This understanding will provide opportunities for interventions and innovative ways to solve problems and make decisions in these local communities. This study provides such an understanding and it is envisaged that innovative interventions will take place in the San community of Platfontein.

\section{Knowledge Management and the Nature of Knowledge}

Within the context of $\mathrm{KM}$, the dynamic nature of knowledge is evident. It is therefore essential for individuals to have a good understanding of knowledge itself if $\mathrm{KM}$ is to be successful. According to McInerney (2002:1009), "knowledge is the awareness of what one knows through study, reasoning, experience or association, or even through various other types of learning". Merriam Webster's Collegiate Dictionary (2002) refers to "knowledge" as the acquaintance with or understanding of a science, art or technique. McInerney (2002:1010) indicates that knowledge is carried, flows, transfers and is obtained by personal relationships over a period of time. Furthermore, knowledge is always changing and is in a state of flux as a result of the experience and learning of the knowledge holder; it is used to overcome barriers, influence decision-making and assist individuals to accomplish their tasks 
and desired goals. It is acquired by individuals actively through sensory stimulation, listening to and observing others, reading, and being aware of feelings, life experiences and learning processes. This is what gives knowledge its dynamic nature, which has captured the attention of researchers and led to KM.

KM may be seen as the application of the collective knowledge of the entire organisation's workforce (or community) to achieve specific goals (De Brun, 2005:3). Furthermore, De Brun indicates that the aim of $\mathrm{KM}$ is not to manage all knowledge, but only that knowledge which is important to the organisation, and to ensure that people have access to this knowledge where and when they need it; that is, the right knowledge in the right place at the right time. $\mathrm{KM}$ is based on the notion that the most valuable resource of an organisation (or community) is the knowledge of its people and how well people use this knowledge to achieve goals and share their knowledge with each other.

Mtega et al. (2014:192) indicate that KM involves the creation, manipulation, storage and sharing of knowledge among people in a community of practice. A further way of looking at KM is suggested by Lwoga, Ngulube and Stilwell (2010:176) - as a system of actions upon knowledge, which includes the establishment of strategies and procedures with the use of appropriate technologies so that the acquisition, storage, conversion, sharing, application and generation of knowledge can be effectively performed. Furthermore, the goals of these activities are to ensure that knowledge is effectively used for problem-solving and decisionmaking. KM approaches, theories, practices and principles can also be effective mechanisms for managing IK (Lwoga, Ngulube \& Stilwell, 2010:175).

Ziemiańczyk, Krakowiak-Bal and Mikuła (2014:48) regard KM systems as sets of principles, methods, means, knowledge (including information), people, networks and their interrelations, which make it possible to adopt and realise strategies and tasks of KM to reach the organisation's goals. The authors further assume that one of the basic goals of KM systems concerning rural or community development is obtaining the desired level of competitiveness through generating and applying knowledge resources that are characterised by rarity and innovativeness.

\section{1 Types of Knowledge}

Knowledge is usually classified into two different types, namely, tacit and explicit knowledge. Explicit knowledge is regarded as "knowledge that can be or has been explained, articulated, recorded or documented while tacit knowledge (sometimes also referred to as implicit knowledge) is usually unspoken and hidden and can be reflected in the skills and experiences that an individual displays over a period of time" (McInerney, 2002:1012).

De Brun (2005:6) refers to tacit knowledge as knowledge that people carry in their heads; it is more an "unspoken understanding" about something. This knowledge is very difficult to write down in a document or to capture in a database. De Brun also relates that in most instances, the individual is not aware of the knowledge that they themselves possess and the value that it may have for others. This is one of the reasons why tacit knowledge is viewed as more valuable than explicit knowledge: it can provide individuals with context, place, ideas and experiences and it also requires extensive personal contact among individuals and mutual trust before the knowledge can be shared.

Kingston (2013:3) categorises knowledge as follows: 
- Explicit knowledge: knowledge that has been written down, described verbally, or captured in diagrams or documents.

- Symbolic experiential knowledge: knowledge gained from experience that the knowledge holder knows that they possess. This knowledge can be in the form of words or concepts; hence it can be verbalised or recorded, but never has been.

- Non-symbolic experiential knowledge: this is knowledge that is gained from experience that is not in the form of symbols but in some other form such as numeric, geometric, perceptual or physiological. The owner of this knowledge knows that they have it but may find it very difficult to verbalise.

- True tacit knowledge: this is knowledge that a person possesses but does not know that they have. True tacit knowledge is often also taken to include factors that affect decision-making, where the person is not necessarily conscious that they have the knowledge or that they are using it.

It is evident from the above categorisation that tacit knowledge is of great value for decisionmaking and it can be seen as the most important aspect of KM.

De Cagna (2000:24) regards the knowledge that exists in an organisation as "common knowledge" that everyone in the organisation has access to it. It is this knowledge that gives the organisation its competitive advantage against other organisations. This common knowledge is regarded as the most important knowledge and the knowledge asset that makes the organisation competitive in the marketplace. The common knowledge is created in the organisation from the experience of doing certain tasks, projects and activities and is unique to that specific organisation, whereas other knowledge can be easily obtained from books, journals etc.

According to Zack (1999:47), "potentially explicable knowledge that has not been articulated represents a lost opportunity to efficiently share and leverage that knowledge. If competitors have articulated and routinized the integration and application of similar knowledge, then they may obtain a competitive advantage". To ensure that potentially explicable knowledge of the San community is articulated and represented for all to share and benefit from, the management of this knowledge is vital.

\subsection{Indigenous Knowledge vs Scientific Knowledge}

According to the World Bank (1998:i), IK is unique to a particular culture and society. It is also the basis for local decision-making in fields such as agriculture, health, natural resources management and other activities, and is embedded in community practices, institutions, relationships and rituals. IK can further be regarded as tacit knowledge that is not easily codifiable.

Mbatha (2013:173) suggests that IK may be seen as knowledge that an indigenous or local community accumulates over generations of living in a particular environment. Various terms are used to describe this knowledge, such as, traditional knowledge, local knowledge, indigenous technical knowledge, community knowledge and rural knowledge. Furthermore, IK has an association with local experiences and historical reality. This makes it unique to a specific community and it plays an important role in defining the identity of that community. Mbatha (2013:173) also recognises that IK represents all the skills and innovations of the 
people of a community and embodies the collective wisdom and resourcefulness of the community as a whole.

Kaniki \& Mphahlele (2002:17) regard IK as a "cumulative body of knowledge that generated and evolved over time, representing creative thought and actions within individual societies in an ecosystem of continuous residence, in an effort to cope with an ever-changing agroecological and socioeconomic environment". They further define IK as being the sum total of knowledge and skills that are possessed by people belonging to a particular geographic area. It is this knowledge that enables them to benefit from their natural environment. Since this IK and skills and innovation are shared over generations, each new generation is constantly adding to this knowledge and adapting it to fit in with the changing situations within the community and the environment. Hence, IK is fluid and may not necessarily be usable within a formal structure or organisation.

IK differs from the more scientific knowledge that is generated in universities, research institutes and private companies and it is used mainly by communities on a more local level for decision-making. Van Wyk (2004:3) indicates that the fundamental difference between IK and scientific knowledge is that science is searching for information of universal significance which is not context-related, while IK is a social product that is closely linked with, or even restricted to, a specific culture and environmental context.

Ristroph (2012:40) suggests that some of the conflict between community and scientific knowledge lies in the struggle for power between communities and government agencies. Furthermore, communities that have no control over decisions made regarding their environment and resources may naturally distrust those who are making the decisions (Ristroph, 2013:90).

The IK that exists in the San community at Platfontein may be referred to as the tacit "common knowledge" of the community and the assets of the knowledge-holders, which is used for decision-making by the individuals who belong to this community. This is what makes this community unique. Hence the management of this IK is essential for the sustained survival of the Platfontein San community. In this study, IK is also referred to as endogenous knowledge, which means viewing the world from the vantage point of local people (the San community) who are independent of the more dominant Eurocentric and Westernised world views (Velthuizen, 2014).

\section{Research Methodology}

This study is part of a larger community-based participatory research project with the San community of Platfontein that has been conducted by the Institute of Dispute Resolution (IDRA) at Unisa. The overall research question for the project can be stated as: "What are the dispute resolution practices of the San of Platfontein that can contribute to alternative dispute theory and practice in Africa?"

Since this study is participatory and involves community engagement, it is led by the San community and the academic researchers follow the lead of the community. The involvement of community members (or those who have assimilated into and learned from a community) in data collection can help overcome the tendency to distrust "outside" agencies or researchers (Ristroph, 2012:176). Also, community members may be more successful than outsiders at gathering tacit information that would otherwise be lost in the communication gap between 
the community and those seeking the knowledge. This was therefore chosen as the most appropriate way to conduct the study in the San community.

The project is divided into three phases:

- Phase 1: Discovery phase - during this phase field researchers were trained to assist in conducting the interviews; initial interviews were conducted with the community; focus group meetings were held; and conflict mapping and interpretative workshops were held in order to test the methodology and to produce an initial conflict map.

- Phase 2: Interpretation and design phase - this phase involves continuous data gathering through interviews, focus groups and integrated workshops to codify specific dispute resolution practices. Community conversations that include several interest groups will confirm the design of the dispute resolution architecture. It is envisaged that these "conversation maps" will be developed into interventions in phase 3.

- Phase 3: Delivery - a programme of action will be launched in the form of a series of capacity-building intervention projects to achieve adaptive change in the community.

This article is based on phase two of the project, which involved integrated workshops in the form of a large group retreat that was attended by the San community and invited Unisa scholars. During this retreat, a series of locally relevant "provocative propositions", identifying statements that replace "what is" with "what might be", were developed. Since the San community is mainly an oral, indigenous community, with unique IK, the management of this knowledge is essential within the dispute-resolution and decision-making context. Hence oral interviews with members of the San community were used to elicit the desired information for this study.

The main research question for this paper is therefore: "What $\mathrm{KM}$ processes and practices are used in the modern San community for decision-making and knowledge sharing?

In order to fully address this main question, the study objectives were to:

- determine who are the modern San of Platfontein;

- identify the nature of the knowledge that exists in the San community;

- understand where the modern San obtain their information when they need to make decisions; and

- identify what possible KM processes/trends are being used in the San community without community members being aware of them.

From the above methodology, the transdisciplinary nature of this study is clear. Different groups of individuals are involved in the study including experts, knowledge workers, academics and the San leaders and community workers. These groups bring together their different experiences, insights, values, beliefs and innovative thinking and leadership styles and learn from each other. In this situation, the individuals form an intellectual capital pool of people with transdisciplinary insights, holistic knowledge, cultural awareness and innovative thinking (Velthuizen, 2011:125).

KM processes, and especially IK within the San community, cannot be conducted via traditional methods of acquiring knowledge. Furthermore, the San community have complex problems, leadership and culture; to deal with this complexity, a more innovative approach to determining how the San community make use of KM processes to manage their knowledge for decision-making was essential. Therefore a transdisciplinary approach was adopted to 
make sense of the various levels of reality that exist in the San community of Platfontein. According to Velthuizen (2012:55), "in order to discover reality, critical reflection is required of the unseen factors such as values, motives and influence that are hidden in a metaphysical dimension that the human senses are limited to observe and analyse and this is an important characteristic of transdisciplinarity".

\section{The San as Indigenous Community}

The San people are regarded as the oldest people of Southern Africa; they are hunter-gathers who have managed their scarce water, plant and animal resources within a shared economy and egalitarian society for centuries (Broyhill, Hitchcock and Biesele, 2010:16). With the onset of colonisation, the San, like other minority groups, lost their traditional livelihoods and became a marginalised society. This is largely because their cultural differences and practices were misunderstood; they were not considered to have any conventional leadership or wealth and they did not produce any goods or services that contributed to the economy of the country.

The loss of their land and resources has had an extensive negative impact on the San, especially in terms of limiting their prospects for living according to their age-old culture (Kxao Moses \& Thoma, 2006:3). These authors further allude to the fact that the San consider their cultural practices to be the backbone of a healthy and socially intact community. Kxao Moses and Thoma (loc. cit.) further explain that the "disruptions to an indigenous culture caused by the injustice of land and resource dispossession has affected the community to such an extent that they are unable to uphold their traditional consensual decision-making where democracy was practised through the vehicle of community consensus". This means that if decisions did not have the general approval and backing of the members of the community, they were never implemented. Colonisation has devastated the social and political institutions that once existed within the San communities.

Sena (2010:4) identified certain characteristics of communities that claim to be indigenous in Africa. These are:

- political and economic marginalisation rooted in colonialism;

- de facto discrimination, often based on the dominance of agricultural peoples in the state system (e.g. lack of access to education and health care for hunters and herders);

- the particularities of culture, identity, economy and territory that link hunting and herding peoples to their home environments in deserts and forests;

- the physical distinctiveness of some indigenous people such as the San, which makes them subject to specific forms of discrimination

These characteristics are prevalent in the San of Platfontein, thereby defining them as indigenous. They are the holders of vast amounts of unique knowledge that could be beneficial to Western societies.

\section{The Modern San of Platfontein}

From the study it became evident that the new generation of the San, which is referred to as the modern San, are becoming more Westernised and are slowly losing their traditional 
culture and values. The interviews with members of the San community (Sewdass, 2014a) revealed the following:

- The modern San are comfortable with moving out of the community and will easily do this, especially if they have job opportunities. These individuals do not have the experiences of the older generation, e.g. moving from Angola to South Africa. The changes taking place around them in South Africa have a significant influence on the modern San.

- They prefer to be in South Africa where there are more opportunities for them and a better quality of life than in Botswana or Angola, and an opportunity to get an education. The modern San have access to educators and are able to speak and read English.

- They have access to television and the freedom to choose their own destinies, even though these are still quite limited. They are no longer forced to follow the traditions and customs of the San.

- The modern San can sometimes be overwhelmed, as they are expected to take on both modern and traditional roles.

- However, since they do not carry the burdens of the past such as being displaced from their land, this does not impact them in the same way as it does the elders in the community.

- The language they speak determines their socialisation. It is difficult for them to interact with non-San people because they are teased and mocked when they speak their own language, therefore most speak Afrikaans and only use their mother tongue when speaking to other San.

- The modern San are self-sustaining just as their traditional ancestors were, and they prefer to live on their own and take care of themselves. However, today they rely more on Western culture than living off the land.

- The legal system in South Africa is very well known to the modern San and they do not use the traditional means of dispute resolution. The traditional courts do not work very well because of the leadership problems that exist in the San community. Once a person has been tried in the traditional court, they have a tarnished reputation and their credibility is questionable; this deters others from doing the same thing.

- The modern San are more sociable and they go out with friends and spend time with others. They are free to do as they please and go anywhere.

- Even if the modern San relocate from the community, they will return to visit their families.

- Modern San marriages are no longer arranged by the elders and family members. While most traditional San live together and trust each other, the modern San prefer to go to the Department of Home Affairs to get married. They feel safer and more protected this way if anything happens and the marriage does not work out.

- There are smaller groups among the San (based on where they lived in the past, e.g. Buma Khwe, Mahiro Khwe, Garangi Khwe, Phuto Khwe) that still want their own leader from their own village to be the leader of the community. Mainly the leadership problems lie with the older generation and not the modern San. 


\section{The Use of Knowledge for Decision-Making by the Modern San Community}

The study examined how and where the modern San community obtain information and use it to make decisions on things such as careers, personal development etc.

According to interviewees Kasivi and Hanzie (Sewdass, 2014a), the modern San usually consult their parents or very close relatives when making any decisions. This is because most of them have trust issues and therefore find it easier to go to their parents or close relatives as they trust them more than outsiders. Most of the new-generation San make their own decisions as opposed to having decisions made for them by their parents or others in the community, as was done traditionally. These younger-generation San also use their mobile phones or school computers to access the internet; once they have the required information about study opportunities, careers or social aspects, they use this information to make decisions. They consult the Department of Arts and Culture's library and the museum in Platfontein to get information about their own (San) culture. In this way they are able to still remain in touch with their traditions, although most of them do not practise these traditions and customs.

They also indicated in interviews that they have very restricted career and job opportunities because of the language barriers that exist between them and the organisations and education institutions. Most San speak Afrikaans. The subjects that are taught in the schools also restrict their opportunities in certain career fields; for example, in order to become a doctor, one must do very well in maths and science and in most cases these subjects are not available at their schools. Hence the modern San do not meet the requirements to study in these fields. Most San people feel marginalised as a result of their language and culture, and because most are very poor, they do not feel as though they fit into the wider society. As a result most are very reserved and introverted and would rather mingle and interact with their own community. Hence the knowledge they obtain is restricted to knowledge from the small group that the modern San is associated with and not necessarily from the larger community. For this reason they are probably missing out on the more useful and expert knowledge of community knowledge holders.

The modern San go to Further Education and Training (FET) Colleges and learn how to use computers, as they believe that this will help them to get jobs. Although there is very little support available for the San students when making decisions about careers and further education opportunities, some students do consult their teachers for advice about these matters. The modern San are more reliant on scientific knowledge for their development and to fit into their environment, as is reported by Kasivi and Hanzie (Sewdass, 2014a).

The traditional leaders are usually consulted to teach people how to do the trance dance, which is usually done by very well-trained and knowledgeable people. Trusted elders and adults are usually consulted to assist in certain more traditional issues. Someone who is trusted and has the knowledge in the community about certain issues is mainly consulted for oral information and knowhow.

Most youth have adopted Christianity and go to church, so a great deal of advice and information is sought through the church. Some youth forget about their traditional leaders and are keen to avoid them and go to the pastor. Even some traditional elders are adopting Christianity, but they still try to retain their traditional culture.

The South African San Institute (SASI) is a knowledge centre that used to record oral (audio) documents, music, videos and stories about the San, but this no longer happens due 
to a lack of funding. As a result, there is a fear that much will be lost, since no one is recording the traditions and culture of the San. It is evident from this study that consensus decision-making at village or community level is no longer the norm, which was usually the case in the San community.

\section{Knowledge for Conflict Resolution in the San Community}

Leadership conflict is very common in the San community. In the past the community usually decided who the leader in the community was, but because the different San tribes (!Xun and Khwe) are forced to live together there are problems with the leadership. Each tribe wants its own leader to be in charge and this causes a lot of friction in the community. The leaders are expected to represent a whole community in a new democratic system that has both old and new social values which clash with each other (Broyhill, Hitchcock and Biesele, 2010:11).

To complicate the situation, there are also the political leaders from South Africa's political parties, such as, the African National Congress (ANC), the Congress of the People (COPE) and the Democratic Alliance (DA). Since the ANC is the majority party in the Platfontein region, the San community are coerced into voting for them otherwise they do not get any jobs in the community, especially government posts. It is therefore very difficult for them to elect the political party that they really want. So there are two forms of leadership in the San community: the leader of the community and the political party leader.

The leader that is elected in the community is elected once in five years and the vote is based on trust from having lived with this person; blood lines are also a factor in voting. People vote for their own tribe. The leader is then able to assist the San community with jobs, career opportunities and liaising with companies for jobs and other assistance for the community, such as negotiating Reconstruction and Development Programme (RDP) houses.

Besides having a community leader, there are also traditional leaders from each individual clan who advise and assist in making decisions and conflict issues. Decisions are made by first consulting the community leader, who then goes to the traditional leaders to decide what has to be done to resolve problems. A date is then set and the parties involved in the dispute are given the opportunity to tell their side of the story before a decision can be made. Once the decision is made, it is accepted by both parties.

Modern South African law also applies. In most cases, depending on the severity of the problem, the people seek to apply South African law by approaching the police and the courts, e.g. in murder cases. The guilty individual must serve the sentence handed down by the court; once the sentence is completed, he must then return to the community and serve the sentence/punishment determined by the traditional leaders in conjunction with the families involved. In some cases the decision made is for the perpetrator to compensate the family of the aggrieved; these decisions are usually accepted and the parties cooperate to resolve the issues.

Rituals are then conducted to cleanse the individual, especially if a murder was committed, and he is then able to move on with his life. For example, if a murder was committed, after serving the sentence in prison, the guilty person returns to the community and a goat is slaughtered to cleanse and remove the curse, otherwise the individual will be haunted forever. This process of dispute resolution - first following modern South African law and thereafter 
the traditional processes - is very long and tedious for the parties involved, and it is anticipated that during this time the anger and confusion remains in the community and people find it difficult to carry on as normal. During this time very little knowledge is shared among the people in the community.

Crawhall (2007:21) suggests that:

[the] problem comes when the economy or environment that supported the society is
threatened and transformed. The society may adjust itself and move forward, but
particularly where another society, with a different economic mode or technological
capacity, occupies the territory and permanently disrupts the transmission of cultural
resources, there is a risk of the intergenerational system collapsing. This collapse is
manifested in ethnic bias and discrimination: one group absorbs an identity of
inferiority, which can lead to language abandonment, loss of identity, and frequently a
loss of self-esteem, expressed through substance abuse, anger, violence and depression.

This is the situation with the San in Platfontein, as was revealed in the data collected from the community (Mkatshelwa, 2014b) which indicated that many modern San of Platfontein feel discriminated against, experience loss of self-esteem and suffer from depression. This has resulted in them turning to drugs, alcohol and violence. Hence most of these San are often in conflict with the law or the community elders due to their bad behaviour, and they also find it difficult to hold a permanent job. Drugs, violence and alcohol are therefore the main causes of disputes in the community (Mkatshelwa, 2014b).

Broyhill, Hitchcock and Biesele (2010:5) further state that the relocation of the San to government settlements in Platfontein has separated families and placed the San next to different tribes and ethnic groups with whom they are not accustomed to live. They were relocated to a more urban setting and have to live alongside another society whose social status and economic standing are much higher. These communities have a more entrepreneurial mind-set; they are the ones running the shops and making money in the community and they have more political influence and more resources, thereby leaving the San feeling inferior and marginalised.

Most of the modern San are ashamed to follow tradition, although their families still do (Sewdass, 2014a). They are sometimes afraid to speak their mother tongue for fear of being judged as useless, being abused or not taken seriously by companies and individuals outside the San community. Hence many of the modern San of Platfontein feel discriminated against and experience loss.

\section{Possible KM Processes and Trends the San Use Without Knowing It}

According to Adam (2007:4), KM tools, processes and platforms could also be adapted to capture and disseminate IK. However, it is important that before these processes and tools are used, a thorough understanding of the context of local innovators and those who benefit from IK is obtained.

According to the World Bank (1998:ii), learning from IK by first investigating what local communities know and have, can improve one's understanding of local conditions and provide a better context for activities that are designed to help these communities. 
KM processes, as identified by De Brun (2005:57), are regarded as those activities or initiatives that are put in place to enable and facilitate the creation, sharing and use of knowledge for the benefit of the entire organisation (or community). While these processes are traditionally used in organisations, the study found that they are also practised by the San community at Platfontein, which does not even realise that they are using them. Examples are:

- Conducting knowledge audits to identify knowledge needs, knowledge resources and knowledge flows. Indigenous communities are usually close-knit units and their social, political and economic organisation revolves around the family, clan and/or the institution of the traditional leader (Ikoja-Odongo, 2004:173). Hence the traditional leaders and the elders in the community knew the scope of the knowledge of their community. Furthermore, these leaders and elders had a good idea of what opportunities were available in their own environment and what was good for the community and what posed a danger or harm to the community. Ikoja-Odongo (2004:173) further indicates that "through the process of discriminative selection, indigenous communities are able to audit what Indigenous Knowledge practices they need to retain and what to drop in every aspect that affected them". The San community in Platfontein already have structures in place that enable them to exchange knowledge. For this reason, they can audit what works and what does not work in specific instances, and they also know who the expert knowledge holders are in the community. According to interviewees Kasivi and Hanzie (Sewdass, 2014a), trusted elders and adults are usually consulted to assist in certain more traditional issues within the community. Depending on what information is needed, the modern San will consult the relevant knowledge holder: for example, if they require information to guide them in decisions regarding their careers, then their teachers are consulted for such advice.

- Creating knowledge strategies to guide the overall $\mathrm{KM}$ approach. Indigenous communities usually have unwritten strategies and procedures for the diffusion and transfer of knowledge and practices to the community. They also rely to a large extent on their environment for information to help them to make choices and decisions that affect the entire community: for example, they know how to cope when there is a drought and what foods they should rely on during this time. In the San community, the knowledge systems are located within cultural systems that exist in Platfontein. The language spoken by each culture restricts the sharing and use of knowledge to people from a specific culture who speak and understand that language. Knowledge that is required for decision-making is therefore mainly sought from people within that culture. According to Crawhall (2006:21), "these cultural systems reproduce themselves without any conscious efforts by the people who live in them". Parents raise children with certain value systems and teach them how to do certain things.

- Connecting people with people to share tacit knowledge, using approaches such as communities of practice and learning events. According to Kaniki and Mphahlele (2002:28), in KM, a community of practice can be seen as an interdependent group of people living in the same information space and interacting with each other through resources and other common relationships. This definition of a KM community of practice ties in closely with the definition of indigenous communities or traditional local communities, where learning and sharing of knowledge and skills takes place by means of IK sharing among members of a community and is part of the daily life of 
the community. The knowledge is tacit in nature and it is embedded in the practice of certain activities and experiences of the knowledge holders; the knowledge is learned or exchanged through personal communication and demonstration such as from parent to child, neighbour to neighbour, religious leaders to the members of the congregation, or master to apprentice.

- Connecting people with information to share explicit knowledge using approaches such as best-practice databases, and using content management processes to ensure that explicit knowledge is current, relevant and easily accessible. The modern San, who would originally have learned through experiential hunting and gathering, "learning by doing", are now learning through a mixed format of IK and modern scientific knowledge as they are introduced to the new educational systems that are available to them, go to school and have access to libraries, the internet and other technological systems. The study found that the modern San are aware of the people and places that can help them with current explicit knowledge that they require for decision-making and problem-solving. They also consult best-practice databases in order to familiarise themselves with what the practice in the modern world is, and want to learn and be competent in these activities. According to Kasivi and Hanzie (Sewdass, 2014a), the younger-generation San use social media on their mobile phones and school computers to search the internet; once they have accessed the required information about study opportunities, careers or social issues, they use this information to make decisions.

- Creating opportunities for people to generate new knowledge through collaborative working and learning. The adults or elders in the San use IK a lot, while the younger generation use a combination of IK and modern knowledge when making decisions. The elders do not mind if the young, modern San follow modern practices but they would like to see a synergy of traditional methods with modern methods still being practised. They would like the younger generation to at least know and understand their own culture, practices and origin, even if they do not follow the same lifestyle. They must have a sense of belonging (Sewdass, 2014b). The elders in the San community recognise the importance of creating new opportunities for the young San to generate new knowledge and are in the process of negotiating with Unisa to provide training and learning interventions to the younger generation to assist them to develop new skills and competencies and then take these back to the community and share them with the other members in the community. One such skill is computer and ICT usage.

- Introducing processes to help people seek and use the knowledge of others, such as peer assist. In the San community, the expert knowledge holders (elders) usually assist the others with knowledge that is required for decision-making. Ristroph (2012:116) indicates that it is essential that knowledgeable people from the community be identified as community experts and that these experts are then regarded as the community's knowledge sources for the project. These knowledge experts could then also serve as "peer reviewers" of the information that is collected in community workshops or forums; in this way, the possibility of the researchers only hearing what they want to hear is removed. In this project, the elders of the San community serve as peer reviewers of all the information that is documented before it is disseminated. In this way they make sure that the information is accurate and verify that a true account is provided of the practices of decision-making and dispute resolution among the San community. These individuals also ensure that they convey any new knowledge that 
they acquire through their interaction with the modern world to the community members so that it can benefit them and keep them up to date with what is going on in their environment.

- Teaching people to share knowledge in inspirational ways by using storytelling techniques. In the San community, it was stated that the parents spend a lot of time with the children as there are not many places for the children to visit or outing opportunities for them. Hence, the younger children learn from the adults (Sewdass, 2014b). Stories were also used as memory tools that have helped the San over the generations to remember things, and to guide them through daily activities and decision-making when they are faced with a difficult situation. While the use of stories and myths to pass on strategically important information from generation to generation has been an innovative way of knowledge sharing in the San community, the study found that there is very little, if any, traditional storytelling to assist the modern San to learn about their culture and traditions. They are more Westernised and since they have access to television and other technology, they prefer watching television or playing computer games or spending time with friends rather than listening to the traditional stories.

- Encouraging people to prioritise learning as part of their day-to-day work by learning before, during and after the tasks that they have performed. The San community learns certain activities by means of doing. They have to practise an activity several times before it is perfected, and usually they are guided or supported through this learning process by the expert knowledge holders. The modern San who obtain knowledge and skills from outside the community, such as at university, college, school or from their work environment (those that are employed), are expected to bring this new knowledge and integrate it with the traditional knowledge so it can be used to improve the situation that the community finds itself in or to help to make better decisions that will improve the quality of life of the San community. This constant learning and adapting their own IK allows them to interact better with the environment and to make decisions that will benefit the community.

\section{Recommendations and Conclusions}

This study investigated what KM processes and practices are used for decision-making in the modern San community of Platfontein. A discussion of KM and the nature of knowledge was given to place the paper in context. Since the San community was traditionally an oral-based indigenous community, the discussion of indigenous knowledge and how it compared to scientific knowledge was relevant. The indigenous knowledge that existed in the San community can also be referred to as community knowledge and is tacit in nature. This paper explored how this knowledge is used by the modern San for decision-making. Knowledge is also used to make decisions for conflict resolution, and therefore a discussion of the main conflict situations that exist in the San community of Platfontein was essential. The use of $\mathrm{KM}$ processes and trends by the San community was also identified. The traditional KM processes that are usually applied in organisations in a structured way to assist them to manage organisational knowledge in order to achieve organisational goals, are the same processes that are used by the San community to manage their knowledge so that it can be used for decision-making, even though the San community do not realise that they are using $\mathrm{KM}$ processes. 
The following recommendations are made:

- Although IK or community knowledge may seem to be in conflict with scientific knowledge, it should not simply be disregarded as useless. Instead it is suggested that IK should be looked at more closely to identify the root of a conflict, considering whether it results from different viewpoints or missing information, and to gather more information if possible to address the gap, as expressed by Ristroph (2012:12). It is further suggested that decisions should be based on knowledge that is subject to demonstration or proof, as opposed to unsubstantiated belief, as is usually the case with IK since it is difficult to capture and store.

- A record must be kept and maintained of all the knowledge that the Platfontein community shares. Community structures such as SASI need to continue with their work and can be an important platform for capturing, transferring, exchanging and maintaining the IK of the San community.

- According to Crawhall (2007:21), the challenge is to mobilise youth and elders to identify how their own culture is a resource for them. If they can analyse the process of disempowerment and loss, the next step is the conscious effort to manage their knowledge and cultural transmission systems. Perhaps this study will be the first step in this process.

- It seems that while the San are expected, as indigenous peoples, to become more integrated into Western society and economic systems, their traditional knowledge and practices are being lost. Furthermore, indigenous peoples' languages are the primary vehicle for the transmission of knowledge. Every attempt should be made to listen to the San and to respect their wishes.

- The modern San must have a sense of belonging. Hence, it is important that the teachers in the schools that the San children attend are sensitised to their culture, and perhaps more culturally appropriate curricula could be designed that can prevent the loss of cultural identity and self-esteem among the younger San community. Howard (2010:7) suggests that most learning is embedded in an individual's everyday life and cultural practices. Therefore it is necessary for different communities to understand each other's cultural contexts and to move away from using primary Western models alone to solve problems and make decisions. It is also important to match educational programmes to the local community's learning processes if learning is to be successful for the individuals within the community.

- In order to allow the San community's IK to be transferred from generation to generation and to preserve it and put it to effective use, new partnerships are required between respected bodies (such as IDRA) and the government that can demonstrate their conviction of, respect for and commitment to the San's diversity and culture. This view is supported by Crawhall (2007:14), who states that "creative approaches need to be found to help join up the intergenerational transmission of valuable knowledge and the capacity for literacy and numeracy which may be of use to the younger generations". In the San community it was found that the knowledge, skills, wisdom and competencies still exist, but these are at risk if they are not shared, captured and transmitted to the younger generation.

- In the search for African solutions to African problems, the San community is one community that modern society should be looking at to obtain these solutions and link this knowledge with scientific and technical knowledge. 
- From this study, it is clear that the San people want more autonomy and involvement in matters that impact them. They are keen to manage their own affairs, to be part of decision-making that affects them and not have these decisions made for them by others. Hence it is important to involve the San community in any decision-making process that affects them and to incorporate their ideas and views when decisions are made.

- More learning and exchange networks such as the IDRA project should be encouraged that can facilitate the exchange of ideas, competencies and skills between the San community and other communities.

- The use of IT should be strengthened, as it was found that the modern San are very keen to use technology and, in the form of mobile phones, community radio stations and television, are already doing so. It can be used to give the San community a voice and allow them to express their ideas, values, language and culture, thereby ensuring that it is shared and preserved. This will enhance the modern San's appreciation of their culture and identity. KM tools and techniques such as content management systems, group collaboration tools, journals, blogging and social media platforms, can also be adapted to capture and disseminate the IK of the San community. However, it should be noted that before these tools and techniques can be applied, a thorough understanding must be obtained of the San community and their local context as well as those who will benefit from the use of their IK. This will prevent misuse of the IK.

Ristroph (2012:119) also indicates that the best way to use community knowledge or IK is not to simply put it in a document or a database, but to allow those with the knowledge to actually participate in decision-making. This allows community knowledge to be used at every step of the decision-making process, which can benefit the community as a whole. This project has been able to accomplish this by allowing the San community elders with IK to be part of the project, thereby ensuring that their IK is embedded in the findings and suitable interventions can take place that benefit the San community.

\section{References}

Adam, L. 2007. Information and communication technologies, Knowledge Management and indigenous knowledge: implications to livelihood of communities in Ethiopia. $\begin{array}{llll}\text { Retrieved on } & 22 & \text { September } & 2014\end{array}$ http:/www:unpan/un.org/intradoc/groups/public/documents/undpadm/unpan040822.pdf

Broyhill, K, Hitchcock, R \& Biesele, M. 2010. Current situations facing the San peoples of Southern Africa. Retrieved on 07 September 2014 from: http://www.kalaharipeoples.org/index_htm_files/Current\%20Situations\%20of\%20the \%20San.pdf

Crawhall, N. 2007. Indigenous peoples in Africa. Occasional paper. Norway: Norwegian Church Aid.

De Brun, C. 2005. ABC of KM. Retrieved on 07 September 2014 from http://www.library.nhs.uk/knowledgemanagement/

De Cagna, J. 2000. Exploring common knowledge: an interview with Nancy Dixon. Information Outlook, 4(10): 24-28. 
Editorial. 1993. Indigenous Knowledge and Development Monitor, 1(3): 1.

Howard, S. 2010. Use of indigenous knowledge in environmental decision-making by communities in the Kumaon Himalayas: a dissertation in instructional systems. Pennsylvania: Pennsylvania State University.

Ikoja-Odongo, R. 2004. Mapping and auditing indigenous knowledge capacity in Uganda. In T Bothma and A Kaniki (Eds.). Southern Africa LIS research in progress. ProLISSA: Progress in Library and Information Science in Southern Africa. Proceedings of the third Biannual DISSAnet Conference, 28-29 October. Pretoria, Farm Inn: 173-190.

Kaniki, AM \& Mphahlele, MEK. 2002. Indigenous knowledge for the benefit of all: can knowledge management principles be used effectively? In $\mathrm{R}$ Snyman (Ed.). SCECSAL 2002. From Africa to the world - the globalization of indigenous knowledge systems. Proceedings of the 15th standing conference of Eastern, Central and Southern African Library and information Associations, 15-19 April. Caesars Gauteng Conference Centre, South Africa: 13-36.

Kingston, JKC. 2012. Tacit knowledge: capture, sharing, and unwritten assumptions. Journal of KM Practice, 13(3): 1-13. Retrieved on 09 September 2014 from: http://www.tlainc.com/articl310.htm

Kxao Moses, O \& Thoma, A. (2006). Indigenous San Knowledge and Survival Struggles. In JE Kunnie \& NI Goduka (Eds). Indigenous Peoples' Wisdom and Power. Ashgate. Retrieved on 02 July 2014 from: https://www.ashgate.com/pdf/SamplePages/Indigenous_Peoples_Wisdom_and_Pow er_Ch1.pdf

Lwoga, ET, Ngulube, P \& Stilwell, C. (2010) Managing indigenous knowledge for sustainable agricultural development in developing countries: Knowledge management approaches in the social context. The International Information E Library Review, 42(3): 174-185.

Mbatha, B. 2013. Unpacking four sequential modes of knowledge conversion in managing indigenous knowledge. African Journal of Indigenous Knowledge Systems, 12(2):171187.

McInerney, C. 2002. Knowledge Management and the dynamic nature of knowledge. Journal of the American Society for Information Science and Technology, 53(12):1009-1018.

Merriam Webster's Collegiate Dictionary. 2002. “Knowledge”. Retrieved on 4 January 2002 from: http://www.m-w.com/egi-bin.dictionary

Mkatshelwa, K. 2014b. Theme 2: Types of disputes. Retrieved on 30 September 2014 from: http://hdl.handle.net/10500/13900

Mtega, WP, Dulle, FW, Malekani, AW \& Chailla, AM. (2014). Awareness and use of Web 2.0 technologies in sharing of agricultural knowledge in Tanzania. Knowledge Management Eं E-Learning, 6(2): 188-202.

Ristroph, EB. 2012. Integrating community knowledge into environmental and natural resource decision-making: notes from Alaska and around the world. Washington $\mathcal{E}^{\circ}$ Lee Journal of Energy, Climate and the Environment, 3(1): 81-131. Retrieved on 07 September 2014 from: http://scholarlycommons.law.wlu.edu/jece/vol3/iss1/4 
Sena, K. 2010. African Indigenous peoples: development with culture and identity. Articles 2 and 32 of the United Nations Declaration on the Rights of Indigenous Peoples. New York: United Nations.

Sewdass, N. 2014a. Oral interview with Hanzie Sibongo and Kasivi Dixon, 11 July 2014. Retrieved on 30 September 2014 from: http://hdl.handle.net/10500/14174

Sewdass, N. 2014b. Oral interview with Zeka Shiwarra, 13 July 2014. Retrieved on 30 September 2014 from: http://hdl.handle.net/10500/14175

Van Wyk, C. 2004. Indigenous and modern knowledge. In P Birungi and M G Musoke (Eds.). SCECSAL XVI. Towards a knowledge society for African development. Papers presented at the $16^{\text {th }}$ standing conference of Eastern, Central and Southern African Library and information Associations, 5th-9th July 2004. Kampala, Uganda: $2-11$.

Velthuizen, AG. 2011. Best practices for the management of knowledge for conflict resolution: lessons learned from the Great Lakes region of Africa. International Journal of African Renaissance Studies, 6(2): 118-131.

Velthuizen, A. 2012. A transdisciplinary approach to understanding the causes of wicked problems such as the violent conflict in Rwanda. The Journal for Transdisciplinary Research in Southern Africa, 8(1): 51-62.

Velthuizen, A. 2014. Community-based participatory research, Platfontein San Community. Retrieved on 11 November 2014 from: http://hdl.handle.net/10500/14373

World Bank Report. 1998. Indigenous knowledge for development: a framework for action. Knowledge and Learning Centre: Africa Region.

Zack, M. 1999. Managing codified knowledge. Sloan Management Review, 40(4):45-58.

Ziemiańczyk, U., Krakowiak-Bal, A. \& Mikuła, B. 2014. Knowledge management in the process of building competitiveness and innovativeness of rural areas. Online Journal of Applied Knowledge Management, 2(2): 43-56.

\section{Bibliography}

Bates, P, Chiba, M, Kube, S \& Makashima, D. 2009. Learning and knowing in indigenous societies today. Paris: UNESCO.

Maasdorp, C. 2002. The theme of tacit knowledge in information and KM theory. In T Bothma and A Kaniki (Eds.). Southern Africa LIS research in progress. ProLISSA: Progress in Library and Information Science in Southern Africa. Proceedings of the 2nd Biannual DISSAnet Conference, 24-25 October. Pretoria: Farm Inn: 251-260.

Mkatshelwa, K. 2014a. Conflict and dispute resolution patterns. Retrieved on 30 September 2014 from: http://hdl.handle.net/10500/13899

Raseroka, HK. 2002. From Africa to the world - the globalization of indigenous knowledge systems: setting the scene. In R Snyman (Ed). SCECSAL 2002. From Africa to the world - the globalization of indigenous knowledge systems. Proceedings of the 15th standing conference of Eastern, Central and Southern African Library and information Associations, 15-19 April. Caesar's Gauteng Conference Centre, South Africa: 1-12. 